\title{
Pigeons experience orientation-contingent chromatic aftereffects
}

\author{
JEAN E. ROBERTS \\ Bucknell University, Lewisburg, Pennsylvania
}

\begin{abstract}
Two lines of evidence suggest that pigeons experience orientation-contingent chromatic aftereffects following adaptation to red-vertical and green-horizontal stripes. First, in the experiment described, pigeons responded to achromatic horizontal and vertical stripes as though they were colored. Second, they tended to respond to stripes with colors designed to cancel out the aftereffect as though they were achromatic.
\end{abstract}

Humans report that following alternating inspection of red and black vertical and green and black horizontal stripes, achromatic vertical stripes appear greenish, horizontal stripes appear pink, and diagonal stripes appear achromatic. Since McCollough's (1965) initial report of this orientation-contingent chromatic aftereffect (OCCA), the phenomenon has been intensively investigated (for reviews, see Anstis, 1975, Harris, 1980, Skowbo, Timney, Gentry, \& Morant, 1975, and Stromeyer, 1978), undoubtedly because of its presumed relationship to recent neurophysiological findings (see Held, 1980).

OCCAs have also been demonstrated in one nonhuman species, the rhesus monkey (Maguire, Meyer, \& Baizer, 1980). It is theoretically more interesting, however, to ascertain whether a nonprimate can acquire OCCAs, because many theoretical treatments of OCCAs (see Harris, 1980 , for a review) rely upon characteristics peculiar to the primate visual system. The pigeon is an especially ineresting subject for such an attempt: Its excellent vision has been studied extensively, and there are both similarities and interesting differences between primate and pigeon vision. At the functional level, for example, both classes of organisms have excellent acuity (in pigeon, see Nye, 1968) and color vision (in pigeon, see Wright, 1979). At the physiological level, the classes are similar in having two visual pathways: one (thalamofugal) proceeding from retina to thalamus and then to cortex (in primate) or to telencephalon (in pigeon), the other (tectofugal) proceeding from retina to superior colliculus (in primate) or to the homologous optic tectum (in pigeon) (Webster, 1974). The classes differ, however, in that the thalamofugal pathway dominates for primates, whereas the tectofugal pathway dominates for pigeons. Furthermore, the primate thalamofugal pathway processes both pattern (Hubel \& Wiesel, 1968) and color (De Valois,

I would like to thank J. A. Nevin for collaborating in earlier work on this problem and for the loan of equipment. Reprints may be obtained from the author at Department of Psychology, Bucknell University, Lewisburg, PA 17837.
1965) information. In pigeons, on the other hand, pattern information is largely processed in the thalamofugal pathway (O'Flaherty \& Invernizzi, 1972; Revzin, 1970) but color information is processed in the tectofugal pathway (Yazulla \& Granda, 1973).

Based on the similarities and differences between pigeon and primate vision, a demonstration of OCCAs in the pigeon would make certain models of OCCAs that have been proposed more or less plausible, although no single mechanism would be unequivocally supported or refuted. (This is discussed further below, in the Discussion section.) In addition, further studies, especially ones employing physiological manipulations, would become feasible.

In order to determine whether pigeons experience OCCAs, subjects were first trained to discriminate between one-color slides (red, green, or achromatic) and two-color slides (red-green, red-achormatic, or greenachromatic. All slides contained two orientations of stripes, perpendicular to each other. Next, the birds were exposed to adaptation slides (red and black vertical stripes and green and black horizontal stripes), using parameters known to produce strong OCCAs in humans and thus maximizing the likelihood of detecting OCCAs, should they occur in pigeons. Of interest, first, were the birds' responses to achromatic slides following adaptation: If OCCAs occur, such slides should appear to be twocolored when oriented vertically and horizontally (with pink and greenish aftereffects on the horizontal and vertical stripes, respectively), but should appear one-colored when oriented diagonally (no aftereffects). If pigeons do not experience OCCAs, such slides should appear onecolored regardless of their orientation. Also of interest were the birds' responses to two-color slides with desaturated red and green associated with the vertical and horizontal stripes, respectively: If OCCAs occur, they should cancel out the presumably complementary colors in these slides when oriented vertically and horizontally (so that the slides appear one-colored), but not when oriented diagonally. Similar cancellation techniques have been employed to measure the strength of human OCCAs (e.g., Riggs, White, \& Eimas, 1974). 


\section{METHOD}

\section{Subjects}

Three male White King pigeons, maintained at $80 \%$ of their freefeeding weights, served as subjects. They were housed individually in a room with a 12-h-on, 12-h-off light-dark cycle; sessions took place during the light cycle. Free access to water and grit was available at all times. All birds had had approximately 1 year's previous discrimination training using the same procedure and similar slides to those employed here, in an unsuccessful attempt to train a general one- versus two-color concept.

\section{Apparatus}

The $30.5 \times 32 \times 35 \mathrm{~cm}$ experimental chamber (see Figure 1 in Atak \& Nevin, 1983, for an illustration) included three manipulanda: two standard pigeon keys, positioned $18 \mathrm{~cm}$ apart and $20 \mathrm{~cm}$ above the floor, and, between them, a rectangular sleeve, $5 \times 5 \mathrm{~cm}$ at the opening and $12.5 \mathrm{~cm}$ long, into which the pigeon could insert its head. A backprojection screen was located at the end of the sleeve, and a photocell, placed $3 \mathrm{~cm}$ beyond the sleeve opening, allowed detection of the bird's head in the sleeve. A grain magazine was mounted directly below the opening to the sleeve and $5.5 \mathrm{~cm}$ from the floor. A houselight was positioned $4 \mathrm{~cm}$ above the sleeve opening. The chamber was housed in a larger $60 \times 60 \times 90 \mathrm{~cm}$ box equipped with a fan. An $8 \times 10.5 \mathrm{~cm}$ hole in the box allowed the beam from a Kodak Ektagraphic Carousel projector to enter a shutter located $9 \mathrm{~cm}$ behind the hole and $15.5 \mathrm{~cm}$ from the back-projection screen. Two photocells were positioned at the level of the shutter so that the coded slides could be read as one-color versus two-color or training versus test. Control and recording equipment were an adjacent room. Trial-by-trial data were recorded by hand during one baseline session and during the OCCA test session.

\section{Stimuli}

All training and test slides had black and white stripes, with the stripes in half of the slide perpendicular to those in the other half. The stripes were square waves with a spatial frequency of $5 \mathrm{cycles} / \mathrm{deg}$, which is near the pigeon's peak sensitivity (Nye, 1968). Kodak Wratten filters were affixed to the slides to provide colors; no filter was added to achromatic areas. On one-color slides (red, green, or achromatic), any filter used covered the entire slide. On two-color slides (red-green, redachromatic, or green-achromatic), a different color was associated with the stripes of each orientation. Four levels of saturation were employed for both reds (Wratten filter numbers, most to least saturated: 25, CC40M, CC20M, and CC10M) and greens (58, CC40G, CC20G, and CC10G). Within each class of slides, half had the stripes oriented vertically and horizontally (hereafter called "vertically"), and half had the stripes oriented diagonally. Each color was associated equally with all stripe orientations. Note that slides referred to below as "test slides" are not physically different from the achromatic training stimuli, but were coded differently merely because different reinforcement contingencies were in effect during the test session (see below).

The two types of adaptation stimuli consisted of slides with red and black vertical stripes and slides with green and black horizontal stripes. The stripes were of the same spatial frequency as those of the other slides, since for humans the strongest OCCAs occur when adaptation and test spatial frequencies are the same (Stromeyer, 1972; Teft \& Clark, 1968). Colors were provided by Wratten filter numbers 25 (red) and 58 (green). These filters were chosen because their dominant wavelengths are roughly opposite from each other (and thus, perhaps, complementary) on the pigeon color space (Schneider, 1972). Although it is not mandatory to use complementary colors during adaptation, some investigators have suggested that they may enhance OCCA strength in humans (Riggs et al., 1974).

\section{Procedure}

Daily training sessions consisted of $\mathbf{2 0 0}$ trials in which $\mathbf{4 2}$ slides, half one-color and half two-color, were each presented four or more times. The order of slides was block randomized with no more than three in succession of either type. To initiate a trial, the bird inserted its head into the viewing sleeve, which opened a shutter so that a slide became visible on the back-projection screen. If the bird held its head within the sleeve for at least $1 \mathrm{sec}$, the shutter closed and the two response keys were illuminated. If the head remained in the sleeve for less than $1 \mathrm{sec}$, the shutter closed and the houselight was turned off for $3.5 \mathrm{sec}$, during which head insertions had no scheduled consequences. A peck to one of the illuminated keys extinguished the houselight and both key lights, and initiated a 3.5 -sec intertrial interval, during which the slide advanced and reinforcement (3-sec access to grain) was available following $50 \%$ of all correct responses. Correct responses were defined as right keypecks following two-color slides and left keypecks following one-color slides. Training began with those slides employing the most saturated colors and/or no color. When all birds showed good discrimination, new slides employing the next less saturated colors were added, and so on, until all four levels of saturation were included. A total of 90 training sessions was carried out: $10,9,22$, and 49 with each successive set of slides. (At different points during the last series, Birds 21 and 14 temporarily exhibited strong key biases.)

Following training, one OCCA test session was carried out. Before the session, the birds were first dark adapted for $1 \mathrm{~h}$. (Stromeyer, 1978, has suggested that dark adaptation enhances OCCAs in humans.) They were then restrained from the neck down (put in a plastic pitcher with a hole for the head) and placed in front of the viewing sleeve. While in this position, they were exposed to the two adaptation slides, which were alternated every 3-5 sec for $30 \mathrm{~min}$ (long enough to produce a strong OCCA in humans; White, 1978). Each bird was inspected two or three times during adaptation; in most cases, they were oriented toward the screen and appeared to be looking at the slides.

During the test session, which immediately followed adaptation as described above, 47 slides were each presented four times in the usual procedure. The slides included 8 adaptation slides (classified as onecolor slides); 6 one-color slides, all diagonal to avoid possible OCCAs (CC40M, CC20M, CC10M, CC40G, CC20G, CC10G); 17 two-color slides, 8 diagonal (two each Wratten 25-58, CC40M-CC40G, CC20MCC20G, CC10M-CC10G) and 9 vertical (two each using the CC filters as above plus one each $25-58,25$-achromatic, 58-achromatic); and 16 achromatic test slides, 8 vertical and 8 diagonal. Vertical two-color slides had red associated with vertical stripes and green associated with horizontal stripes. Reinforcement was not available following test slides to ensure that the subjects not be trained during this session to respond in a particular way to these critical stimuli. The 8 adaptation slides, presented together at the beginning of each cycle, were included in order to ensure that the birds actively observe these slides at least a few times, which, it was feared, they may not have done during the passive adaptation period. In addition, including the adaptation slides, along with the one-color diagonal slides, ensured that reinforcement would be available for left keypecks as well as for right keypecks, reducing the likelihood that a bird would simply adopt a right key bias.

\section{RESULTS}

Figure 1 shows the percentage of right keypecks emitted following various classes of slides for each bird during eight sessions: the seven baseline sessions immediately preceding the test session (connected points) and the OCCA test session. Note that right keypecks are correct for two-color slides and incorrect for one-color slides. Each data point represents the average percentage across all levels of saturation and for both stimulus orientations within each of the one-color and two-color classes of slides for a given session. The one-color data include responses to achromatic stimuli during the baseline sessions but not during the test session, when OCCAs were expected to alter the appearance of some of these "test" stimuli. The data for vertical and diagonal achromatic stimuli are plotted separately for the two sessions in which trial-by-trial data were collected.

It is clear from Figure 1 that all three birds exhibited good discrimination behavior between one-color (open cir- 


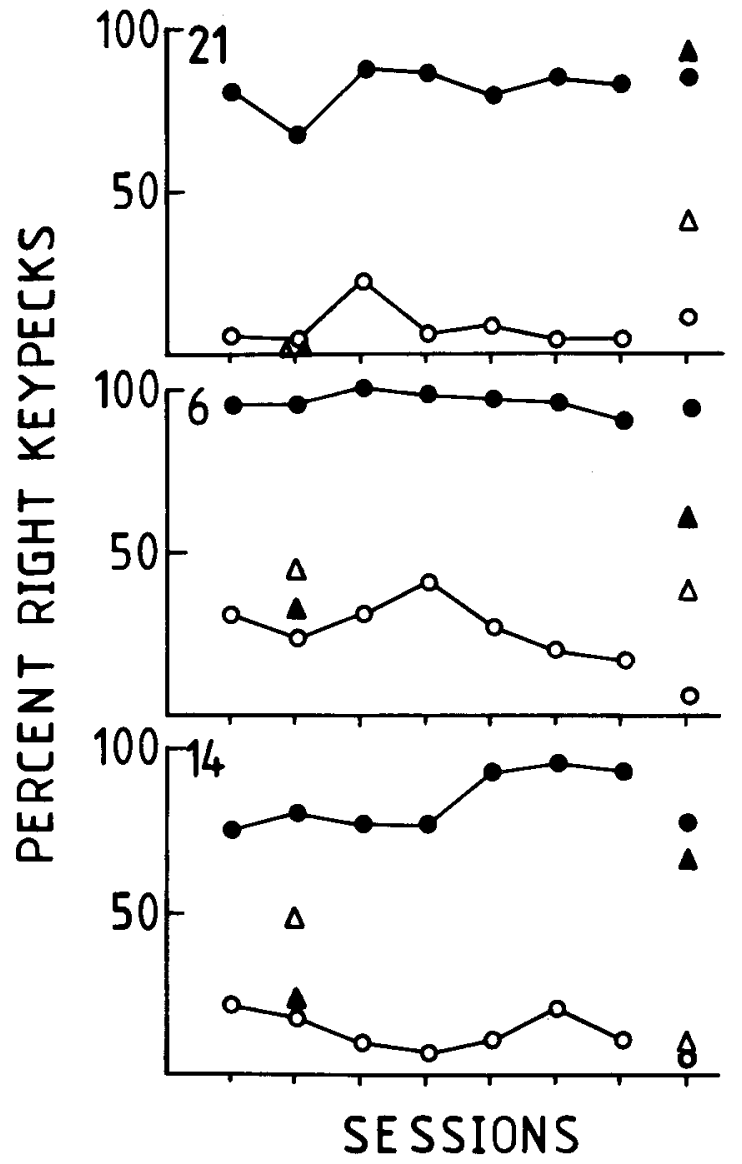

Figure 1. Percentage of right keypecks following various classes of slides during seven baseline sessions and the OCCA test session for Birds 6, 14, and 21. Circles are for two-color (filled) or onecolor (open) slides; triangles are for vertical (filled) or diagonal (open) achromatic (or "test") slides.

cles) and two-color (filled circles) slides during the baseline sessions, and that this differential behavior was maintained at similar levels during the test session. During the test session, vertical achromatic test slides (filled triangles) should appear to have two colors if OCCAs are present, whereas the diagonal achromatic test slides (open triangles) should still appear to be achromatic (one-color). Indeed, all three birds were more likely to peck the right key following vertical than following diagonal test slides. A test of proportions (Ferguson, 1971) showed that the difference between the proportions of right keypecks following the two types of test slides was highly significant for Birds 21 and 14 ( $z=4.53$ and 4.76, respectively) and just reached significance for Bird $6(\mathrm{z}=1.65$, $\mathrm{p}<.05$, one-tailed test). Similar comparisons of the data for vertical versus diagonal achromatic slides during the one baseline session for which these data are available, on the other hand, revealed no significant differences. (The data for Birds 6 and 14 appear in the figure to be different, but it should be noted that only one diagonal and three vertical achromatic slides were presented dur- ing the session, each four times. Also note that the direction of the difference in these cases is the opposite of that found during the test session.) During the test session, it actually appears that Bird 14 was just as likely to peck the right key following vertical and diagonal test slides as he was following two-color and one-color slides, respectively. Bird 6 , on the other hand, was substantially less likely to peck the right key following vertical test slides than following two-color slides, and was more likely to peck the right key following diagonal test slides than following one-color slides. This may have been due to a tendency to tilt his head during inspection of the test slides, such that OCCAs sometimes disappeared from the vertical slides and sometimes appeared on the diagonal slides. It is not clear why Bird 21's behavior following diagonal test slides was different from that following onecolor slides, but was similar following vertical test slides and two-color slides.

The data just described indicate that slide orientation had no effect on responding to achromatic stimuli during the baseline session. However, this conclusion is based on a very small number of observations. In order to further evaluate the effect of this variable, its effect on other classes of slides was examined during the two sessions for which these data were available. Figure 2 shows the percentage of right keypecks as a function of slide orien-

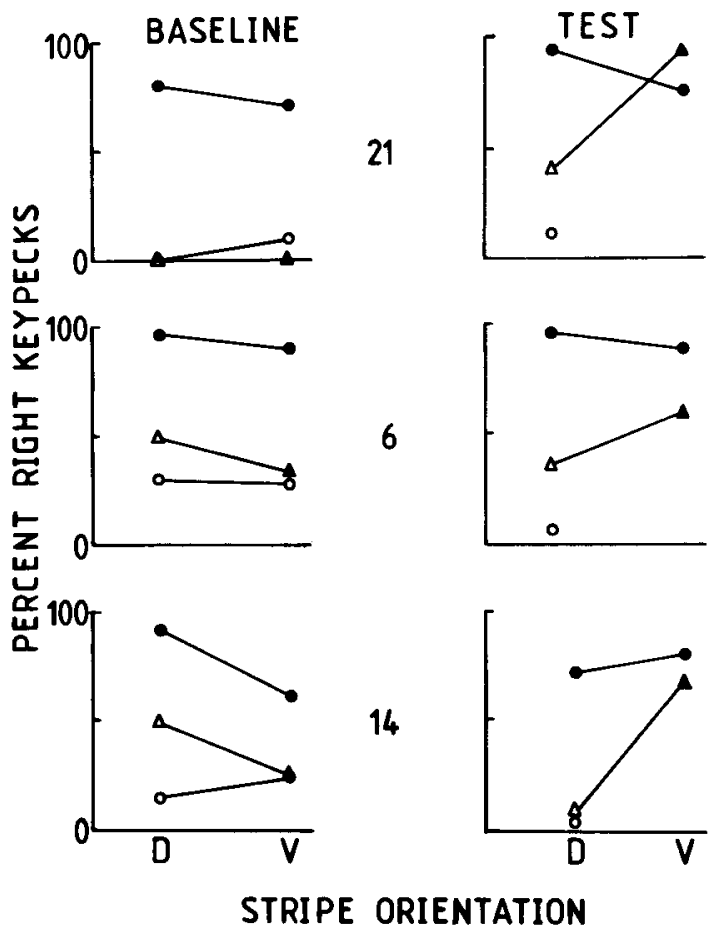

Figure 2. Percentage of right keypecks as a function of slide orientation (vertical, $V$, or diagonal, $D$ ) following achromatic (triangles), other one-color (open circles) and two-color (filled circles) slides for Birds 6, 14, and 21. The functions on the left show the data from a baseline session; those on the right show the data from the OCCA test session. 
tation for achromatic (or test) slides (triangles), other onecolor slides (open circles), and two-color slides (filled circles) for each bird. The functions on the left show the data from the baseline session; those on the right show the data from the test session. A two-way analysis of variance was performed on the baseline data, with chromatic and achromatic one-color slide data combined. The analysis yielded a highly significant effect due to the oneversus two-color variable $[F(1,11)=73]$ but no significant effect due to slide orientation and no significant interaction. A comparable analysis was not possible for the test data because vertical one-color slides were not presented during the test session. However, a test of proportions was performed on the two-color data from this session, comparing the data for vertical and diagonal slides for each individual bird (as was done on the test slide data, described above); none of the differences was statistically significant. Thus, the conclusion that slide orientation had an effect only during the test session and only for achromatic test slides seems justifiable.

Figure 3 shows the percentage of right keypecks emitted following vertical and diagonal two-color slides using the less saturated (CC) filters, as a function of filter

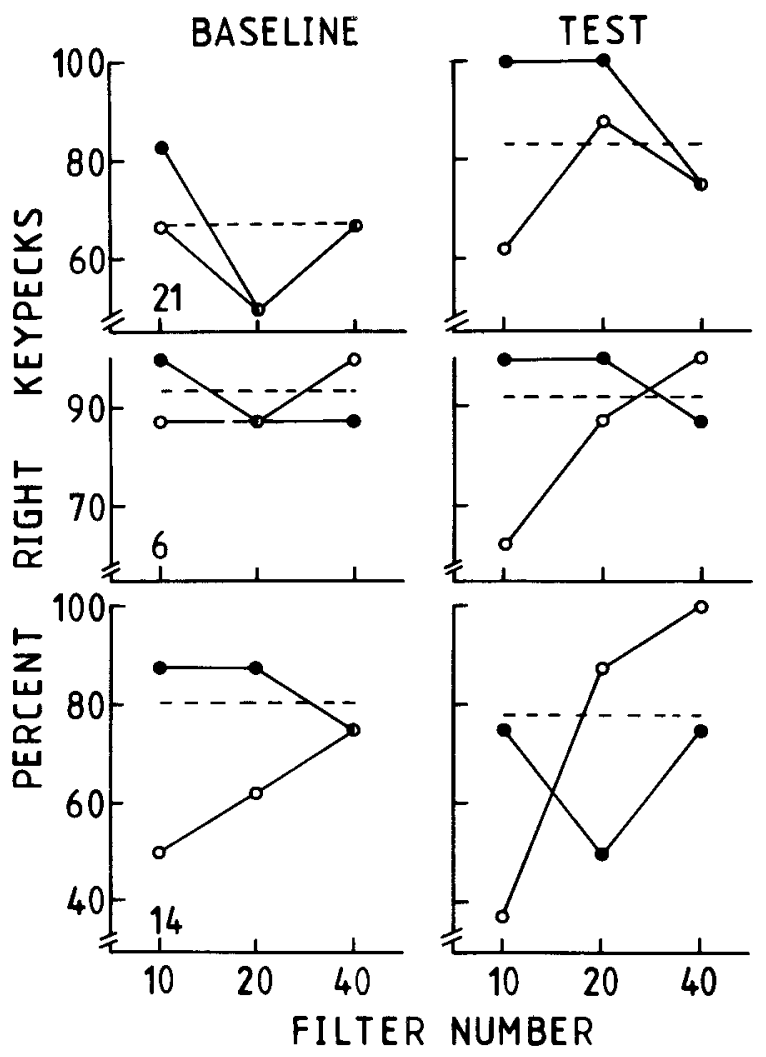

Figure 3. Percentage of right keypecks as a function of filter number (saturation) following vertical (open circles) and diagonal (filled circles) two-color slides for Birds 6, 14, and 21 . The functions on the left show the data from a baseline session; those on the right show the data from the OCCA test session. Dotted lines show the mean percent right for all two-color slides during the session. number (saturation). The right-hand functions show the test session data; the left-hand functions show baseline data from the session 6 days before the test session. Because the two-color vertical slides had red associated with vertical stripes during the test, any OCCAs present should tend to cancel out the filter hues, such that the less saturated slides (with OCCAs of similar saturation) should appear increasingly desaturated, that is, increasingly onecolored. This should not occur, however, for the diagonal two-color slides. Indeed, during the test session, as filter number decreased, all birds were less likely to peck the right key following vertical slides, but not following diagonal slides. In contrast, no consistent trend obtained for either type of slide during the baseline session. These apparent trends were confirmed in statistical analyses of these data: A two-way analysis of variance of the test-session data yielded a significant interaction between the effects of filter number and slide orientation $[\mathrm{F}(2,12)=4.4$, $\mathrm{p}<.01]$, whereas a similar analysis of the baseline data yielded no significant effects.

\section{DISCUSSION}

The data reported in this paper suggest that pigeons can indeed acquire OCCAs. First, the birds behaved as though vertical (but not diagonal) achromatic test slides had two colors. In addition, they tended to respond to the vertical desaturated two-color slides, with hues expected to cancel out the aftereffects, as though they were chromatically homogeneous. The latter result suggests not only that the birds experienced OCCAs, but also that the hues of the aftereffects were approximately the complement of the adaptation colors, as is the case for human OCCAs.

Several. previous unpublished studies have failed to demonstrate OCCAs in pigeons. For example, Erickson (1979) used a procedure that was similar to this one in several respects, especially in attempting to cancel out the aftereffects with desaturated colors. (Pigeons were trained in a go/no-go paradigm in which pecking desaturated red or green was reinforced but pecking an achromatic field was extinguished.) A striking difference between his and the present procedure is that Erickson used only one stripe orientation during testing. Including both orientations on the same test stimulus has been shown to enhance OCCAs in humans through color contrast (Stromeyer, 1978), and may have been critical in the present successful demonstration. Erickson also used gratings with a lower spatial frequency $(2.7$ cycles $/ \mathrm{deg}$ ) than in the present study (5 cycles/deg). Stromeyer (1972) has reported generally that humans have stronger OCCAs on some spatial frequencies than on others. Specifically, larger effects were obtained using gratings of 5 than on ones of 2.5 cycles/deg.

The fact that pigeons experience OCCAs suggests that their perceptual system may be more "plastic" than has previously been thought to be true of birds (e.g., Smith \& Smith, 1962; Taub, 1968). Adult chickens, for example, do not adapt to optical rearrangement (Pfister, 1955, 
cited by Taub, 1968), although newly hatched chicks do adapt to prismatic displacement under some conditions (Rossi, 1968, 1969, 1971, 1972).

The fact that humans and pigeons share the ability to acquire OCCAs also has implications for understanding OCCAs in general. Two different species might share a given behavioral or perceptual phenomenon by either one of two general routes: the phenomenon might be the result either of the same mechanism in homologous or analogous neural structures or of entirely different mechanisms. If we assume that the mechanism underlying OCCAs is the same in humans and pigeons, then certain models that have been proposed can be ruled out because pigeons do not share the necessary neural structures. For example, explanations in terms of adaptation of double-duty (color plus pattern) channels (see, e.g., Harris, 1980) are untenable because these types of information are processed in separate visual pathways in pigeons. ${ }^{1}$ Likewise, the process proposed by Krüger (1979), which relies on inhibitory processes occurring in lateral geniculate nucleus opponent-process neurons, is untenable because opponentprocess neurons do not occur in the analogous structure of the pigeon thalamofugal pathway (dorsolateral complex) (Maxwell \& Granda, 1979). If we assume, on the other hand, that OCCAs could have different underlying mechanisms in the two species, ${ }^{2}$ then the process involved must have an important adaptive significance (as opposed to being nonfunctional, but genetically linked to some other mechanism which does have functional significance): It is unlikely that the two species would have independently evolved with this capacity unless it contributed to the fitness of each. (See Anstis, 1975, and Held, 1980, for proposals of the functional significance of OCCAs.) Unresolved questions, such as whether or not the mechanism underlying OCCAs is the same in the two species and the neural locus of the mechanisms, might perhaps be resolved through studies employing physiological manipulations.

\section{REFERENCES}

ANSTis, S. M. (1975). What does visual perception tell us about visual coding? In M. S. Gazzaniga \& C. Blakemore (Eds.), Handbook of psychobiology (pp. 269-323). New York: Academic Press.

AtaK, J. RoberTs, \& Nevin, J. A. (1983). Chromatic adaptation in the pigeon. Animal Learning \& Behavior, 11, 391-395.

DE VALOIS, R. L. (1965). Analysis and coding of colour vision in the primate visual system. Cold Spring Harbor Symposia, 30, 567-579.

DONNER, K. O. (1953). The spectral sensitivity of the pigeon's retinal elements. Journal of Physiology (London), 122, 524-537.

ERICKSON, L. C. (1979). The McCollough effect in pigeons. Unpublished honors thesis (sponsored by P. M. Blough \& D. S. Blough), Brown University.

Ferguson, G. A. (1971). Statistical analysis in psychology and education (3rd ed.). New York: McGraw-Hill.

HARRIs, C. S. (1980). Insight or out of sight?: Two examples of perceptual plasticity in the human adult. In C. S. Harris (Ed.), Visual coding and adaptability (pp. 95-149). Hillsdale NJ: Erlbaum.

HELD, R. (1980). The rediscovery of adaptability in the visual system: Effects of extrinsic and intrinsic chromatic dispersion. In C. S. Harris (Ed.), Visual coding and adaptability (pp. 69-94). Hillsdale NJ: Erlbaum.

Hubel, D. H., \& WiESEL, T. N. (1968). Receptive fields and func- tional architecture of monkey striate cortex. Journal of Physiology, 195, 215-243.

KRÜGER, J. (1979). McCollough effect. A theory based on the anatomy of the lateral geniculate body. Perception \& Psychophysics, 25, 169-179.

Maguire, W. M., Meyer, G. E., \& Baizer, J. S. (1980). The McCollough effect in thesus monkey. Investigative Ophthalmology and Visual Science, 19, 321-324.

Maturana, H. R., \& Frenk, S. (1963). Directional movement and horizontal edge detectors in the pigeon retina. Science, 142, 977-979.

Maxwell, J. H., \& Granda, A. M. (1979). Receptive fields of movement-sensitive cells in the pigeon thalamus. In A. M. Granda \& J. H. Maxwell (Eds.), Neural mechanisms of behavior in the pigeon (pp. 177-197). New York: Plenum Press.

McCollough, C. (1965). Color adaptation of edge-detectors in the human visual sysem. Science, 149, 1115-1116.

NYE, P. W. (1968). The binocular acuity of the pigeon measured in terms of the modulation transfer function. Vision Research, 8 , 1041-1053.

O'FlAHERTY, J. J., \& INVERNIZZI, G. (1972). Functional organization of the receptive fields of single visual units of the "Wulst" in the pigeon. Bollettino della Societa Italiana di Biologia Sperimentale, 48 , 137-139.

Revzin, A. M. (1970). Some characteristics of wide-field units in the brain of the pigeon. Brain, Behavior and Evolution, 3, 195-204.

Riggs, L. A., White, K. D., \& Eimas, P. D. (1974). Establishment and decay of orientation-contingent aftereffects of color. Perception \& Psychophysics, 16, 535-542.

Rossi, P. J. (1968). Adaptation and negative aftereffect to lateral optical displacement in newly hatched chicks. Science, 160, 430-432.

RossI, P. J. (1969). Primacy of the negative aftereffect over positive adaptation in prism adaptation with newly hatched chicks. Developmental Psychobiology, 2, 43-53.

Rossi, P. J. (1971). Prism-induced negative aftereffects without foodreinforced feedback in newly hatched chicks. Psychonomic Science, 24, 141-142.

Rossi, P. J. (1972). The influence of population density and food dispersion on the development of prism-induced aftereffects in newly hatched chicks. Developmental Psychobiology, 5, 239-248.

SCHNEIDER, B. (1972). Multidimensional scaling of color difference in the pigeon. Perception \& Psychophysics, 12, 373-378.

Skowbo, D., Timney, B. N., Gentry, T. A., Morant, R. B. (1975). McCollough effects: Experimental findings and theoretical accounts. Psychological Bulletin, 82, 497-510.

SMrTH, K. U., \& SMITH, W. M. (1962). Perception and motion. Philadelphia: Saunders.

STROMEYER, C. F. (1972). Edge-contingent color after effects: Spatial frequency specificity. Vision Research, 12, 717-733.

STROMEYER, C. F. (1978). Form-color aftereffects in human vision. In R. Held, H. W. Leibowitz, \& H.-L. Teuber (Eds.), Perception. (Vol. 8): Handbook of sensory physiology (pp. 97-142). Berlin: Springer.

TAUB, E. (1968). Prism compensation as a learning phenomenon: A phylogenetic perspective. In S. J. Freedman (Ed.), The neuropsychology of spatially oriented behavior (pp. 77-106). Homewood, IL: Dorsey Press.

TEFT, L. W., \& Clark, F. T. (1968). The effects of stimulus density on orientation specific aftereffects of color adaptation. Psychonomic Science, 11, 265-266.

WeBSTER, K. E. (1974). Changing concepts of the organization of the central visual pathway in birds. In R. Bellairs \& E. G. Gray (Eds.), Essays on the nervous system (pp. 258-298). Oxford: Clarendon Press.

WHITE, K. D. (1978). Studies of form-contingent color aftereffects. In J. C. Armington \& B. R. Wooten, Visual psychophysics and physiology (pp. 267-281). New York: Academic Press.

WRIGHT A. A. (1978). Color-vision psychophysics: A comparison of pigeon and human. In A. M. Granda \& J. H. Maxwell (Eds.), Neural mechanisms of behavior in the pigeon (pp. 89-127). New York: Plenum Press.

Yazulla, S., \& Granda, A. M. (1973). Opponent-color units in the thalamus of the pigeon (Columba livia). Vision Research, 13, $1555-1563$. 


\section{NOTES}

1. This type of process might, however, occur in the ectostriatal belt, where the two pathways converge. The relevant physiological investigations have not yet been performed in this structure.

2. It is possible, of course, that the pigeon mechanism is similar to that of the primate but occurs at a different neural locus. For example, adaptation might occur at the retinal level where pattern (Maturana \&
Frenk, 1963) and color (Donner, 1953) specificity has been demonstrated; a mechanism such as that proposed by Krüger (1979) might occur in the nucleus rotundus of the tectofugal pathway, where opponent-process neurons have been found (Yazulla \& Granda, 1973).

(Manuscript received January 27, 1984; revision accepted for publication August 13, 1984.) 